\title{
On ranking by using weighted self-normalizing distance metrics in multi-attribute decision- making
}

\author{
Mohamed Souissi ${ }^{a^{*}}$ and Sana Hafdhi ${ }^{a, b}$
}

${ }^{a}$ Laboratory of Modeling and Optimization for Decisional, Industrial and Logistic Systems (MODILS), Faculty of Business and Economics, University of Sfax, Airport Street, Km 4, P.O. Box 1088, Sfax 3018, Tunisia

${ }^{b}$ College of Business Administration, Taibah University, Yanbu, Saudi Arabia

\begin{tabular}{l}
\hline C H R O N I C L E \\
\hline Article history: \\
Received February 2, 2021 \\
Received in revised format: \\
June 2, 2021 \\
Accepted July 62021 \\
Available online \\
July 6,2021 \\
\hline Keywords: \\
Distance metric \\
LSP \\
MADM \\
Normalization \\
SAW \\
Reference ranking \\
Self-normalizing \\
\hline
\end{tabular}

\begin{abstract}
A B S T R A C T
Preliminary normalization is central to the decision process of several popular, recent or completely new multi-attribute decision-making (MADM) methods. However, a number of authors have pointed out serious pitfalls attributed to normalization methods. One major pitfall, which has been identified, is that normalization methods may lead to different final rankings of alternatives when a ranking procedure (RP) based on them is used for solving a MADM problem. The current paper aims to ascertain and illustrate the effectiveness of some RPs based on prominent primary WEighted Self-NORmalizing Distance (WESNORD) metrics and their averages. The effectiveness of the selected RPs is demonstrated by solving a logistics service provider (LSP) selection problem taken from the literature. The results reveal that the RPs considered deliver final rankings of alternatives, which are very similar to the SAW-produced reference ranking.
\end{abstract}

(C) 2021 by the authors; licensee Growing Science, Canada.

\section{Introduction}

Multi-attribute decision-making (MADM) is a prominent branch of operations research and management science. It refers to "making preference decisions (such as evaluation, prioritization, and selection) over the available alternatives that are characterized by multiple, usually conflicting attributes" (Hwang \& Yoon, 1981). In MADM, preliminary normalization (i.e., mathematical transformation of all initial attribute values to eliminate the effects of different scales of measurement before using a given method) is central to the decision process of various well-established, recent or completely new methods. Some of these are: the Simple Additive Weighting (SAW) (McCrimmon, 1968), the Technique for Order of Preference by Similarity to Ideal Solution (TOPSIS) (Hwang \& Yoon, 1981), the TOmada de Decisao Interativa e Multicriterio (TODIM) (Gomes \& Lima, 1992), the Complex Proportional Assessment (COPRAS) (Zavadskas et al., 1994), the VlseKriterijumska Optimizacija I Kompromisno Resenje (VIKOR) (Opricovič, 1998), the Multi-Objective Optimization on the basis of Ratio Analysis (MOORA) (Brauers et al, 2006), the Relative Ratio (RR) (Li, 2009), the Performance Selection Index (PSI) (Maniya \& Bhatt, 2010), the Additive Ratio Assessment (ARAS) (Zavadskas \& Turskis, 2010), the Weighted Aggregated Sum Product Assessment (WASPAS) (Zavadskas et al., 2012), the Weighted Euclidean Distance Based Approach (WEDBA) (Rao \& Singh, 2012), the Multi-Attribute Range Evaluations (MARE) (Hodgett, 2013), the Multi-Attributive Border Approximation area Comparison) (MABAC) (Pamucar \& Cirovic, 2015), the Combinative Distance-based Assessment (CODAS) (Keshavarz-Ghorabaee et al., 2016), the Total Area based on Orthogonal Vectors (TAOV) (Hajiagha et al., 2016), the Double Normalization-based Multiple Aggregation (DNMA) (Liao $\& \mathrm{Wu}, 2017$ ), the Combined Compromise Solution (CoCoSo) (Yazdani et al., 2019), the Proximity Indexed Value (PIV) (Mufazzal \& Muzakkir, 2018), the Simultaneous Evaluation of Criteria and Alternatives (SECA) (Keshavarz-Ghorabaee et al., 2018), the Mixed Aggregation by Comprehensive Normalization Technique (MACONT) (Wen et al., 2020), the

* Corresponding author.

E-mail address: mouhamed.souissi@yahoo.com (M. Souissi)

(C) 2021 by the authors; licensee Growing Science, Canada. doi: $10.5267 /$ j.dsl.2021.7.003 
Measurement of Alternatives and Ranking According to Compromise Solution (MARCOS) (Stevic et al., 2020). Numerous types of normalization methods can be found in the MADM literature (see e.g., Aytekin, 2021; Ploskas \& Papathanasiou, 2019; Shekhovtsov \& Kołodziejczyk, 2020). The most common classical normalization methods are vector normalization, linear max normalization, linear max-min normalization and linear sum normalization.

In the literature, a number of authors have pointed out serious pitfalls associated with normalization methods (e.g., Aytekin, 2021; Bhowmik et al., 2018; Çelen, 2015; Ginevičius, 2008; Jafaryeganeh, 2020; Jahan \& Edwards, 2015; Kaplinski \& Tamošaitiené, 2015; Kosareva et al., 2018; Lakshmi et al., 2019; Milani et al., 2005; Mokotoff et al., 2010; Palczewski \& Sałabun, 2019; Pavlicic, 2001; Podviezko, 2014; Podviezko \& Podvezko, 2015; Vafaei et al., 2018; Shekhovtsov \& Kołodziejczyk, 2020). One major pitfall attributed to normalization methods is that they may lead to different final rankings of alternatives when a ranking procedure (RP) based on them is used for solving a MADM problem.

For at least this reason, the current work aims to ascertain and illustrate the effectiveness of some RPs based on prominent primary WEighted Self-NORmalizing Distance (WESNORD) metrics and their averages (see Section 2 and Section 3 for details). The WESNORD metrics of interest are listed below.

I) The three prominent primary distance metrics involved are:

- Weighted Canberra distance;

- Weighted Gower distance;

- Weighted Wave-Hedges distance.

II) The four averages of distance metrics considered are:

- The average of weighted Canberra and Gower distances;

- The average of weighted Canberra and Wave-Hedges distances;

- The average of weighted Gower and Wave-Hedges distances;

- The average of weighted Canberra, Gower, and Wave-Hedges distances.

In the above, all seven of these distance metrics are normalized and computationally quite simple, and therefore suitable for practical applications.

The main contribution of this work is threefold: First, we introduce the cornerstone concept of WEighted SelfNORmalized Distance (WESNORD) metrics. Second, we define an original ranking index exploiting the duality of normalized similarity and distance metrics. Third, we ascertain that the WESNORD metrics based methodology is worthwhile. We organize the rest of the paper as follows. The next section presents the definitions, notation and ideas related to the WESNORD metrics based methodology. The third section explains how to rank alternatives by using WESNORD metrics. To ascertain and illustrate the effectiveness of the use of WESNORD metrics, a logistics service provider (LSP) selection problem adapted from the paper by Hidouri and Rebaï (2019) is solved in the fourth section. The resulting rankings are then compared to the SAW-produced reference ranking. Finally, the fifth section concludes the article and points out two directions for future research.

\section{Basic mathematical definitions}

Let us start by presenting some basic preliminary mathematical definitions such as normalized distance metrics (NDMs) and normalized similarity metrics (NSMs).

Definition 1 (Muscat, 2014). Let $\mathbb{R}$ denote the set of all real numbers and let $X$ be an arbitrary nonempty set. A function $d$ $: X \times X \rightarrow \mathbb{R}$ is called a distance metric on $X$ if, for all $x, y, z \in X$, it holds:

- $d(x, y)=d(y, x)$ (symmetry),

- $d(x, y) \leq d(x, z)+d(z, y)$ (triangle inequality),

- $\quad d(x, y)=0$ if and only if $x=y$ (identity of indiscernibles).

Consequently, we have that $d(x, y) \geq 0$ (non-negativity) for any $x, y \in X$.

Definition 2 A distance metric $d(x, y)$ is said to be normalized if and only if $d(x, y) \leq 1$.

Note that for nonnegative real numbers, all three below-mentioned distances are WESNORD metrics.

Definition 3 (Lance \& Williams, 1967). A function $d_{C}: \mathbb{R}_{0+}^{n} \times \mathbb{R}_{0+}^{n} \rightarrow \mathbb{R}_{0+}$ is an $n$-dimensional Canberra distance if

$$
d_{C}(x, y)=\sum_{j=1}^{j=n} \frac{\left|x_{j}-y_{j}\right|}{x_{j}+y_{j}}
$$


where $\mathbb{R}_{0+}$ denotes the set of all nonnegative real numbers, and where $x=\left(x_{1}, x_{2}, \ldots, x_{n}\right)$ and $y=\left(y_{1}, y_{2}, \ldots, y_{n}\right) \in \mathbb{R}_{0+}^{n}$.

Definition 4 (Gower, 1971). A function $d_{G}: \mathbb{R}_{0+}^{n} \times \mathbb{R}_{0+}^{n} \rightarrow \mathbb{R}_{0+}$ is an $n$-dimensional Gower distance if

$$
d_{G}(x . y)=\sum_{j=1}^{j=n} \frac{\left|x_{j}-y_{j}\right|}{R_{j}}
$$

where $R_{j}$ is a normalizer, usually equal to the range of the $j$ th attribute.

Definition 5 (Cha, 2007). A function $d_{W H}: \mathbb{R}_{0+}^{n} \times \mathbb{R}_{0+}^{n} \rightarrow \mathbb{R}_{0+}$ is an $n$-dimensional Wave-Hedges distance if

$$
d_{W H}(x, y)=\sum_{j=1}^{j=n} \frac{\left|x_{j-} y_{j}\right|}{\max \left(x_{j}, y_{j}\right)}
$$

In the above, it seems obvious (1) that all three of these distances self-normalize separately the absolute difference between the components of the vectors $x$ and $y$ prior to summing and (2) that the mathematical convention employed is that $\frac{0}{0}=0$. We now present the axiomatic system introduced by Rozinek and Mareš (2021) for NSMs.

Definition 6 (Rozinek \& Mareš, 2021). A function $\operatorname{sim}(x, y): X \times X \rightarrow[0,1]$ is a NSM if, for all $x, y, z \in X$, it satisfies the following conditions:

- $\operatorname{sim}(x, y)=\operatorname{sim}(y, x)$ (symmetry),

- $\operatorname{sim}(x, z)+1 \geq \operatorname{sim}(x, y)+\operatorname{sim}(y, z)$ (triangle inequality),

- $\operatorname{sim}(x, y)=1$ if and only if $x=y$ (identity of indiscernibles),

- $\operatorname{sim}(x, y) \geq 0$ (non-negativity).

According to Rozinek and Mareš (2021), the two statements below hold true:

- Associated with every NDM, $\operatorname{dist}(x, y)$, is a NSM, $\operatorname{sim}(x, y)$, in the sense of definition 6 , given by the equation $\operatorname{sim}(x, y)=1-\operatorname{dist}(x, y)$.

- Convex combinations allow assembling different primary NSMs together to produce a composite NSM.

As a result, convex combinations allow assembling different primary NDMs together to produce a composite NDM. The previously presented definitions and ideas lay the foundation for the WESNORD metrics based RPs as it is shown in the next section.

\section{The WESNORD metrics based methodology}

In what follows, we assume that $m$ alternatives $\left(A_{i}, i=1,2, \ldots, m\right)$ are judged upon $n$ attributes $\left(C_{j}, j=1,2, \ldots, n\right)$. Moreover, we denote by $a_{i j}$ the nonnegative crisp attribute value of each alternative $A_{i}$ with respect to the attribute $C_{j}$. We also denote by $W$ by the vector of attribute weights, $\left(w_{1}, w_{2}, \ldots, w_{n}\right) \in[0,1]^{n}$ satisfying $\sum_{j=1}^{n} w_{j}=1$.

The following enumerated list represents the selected WESNORD metrics to be used:

I) The three primary WESNORD metrics:

1) The weighted Canberra distance $d_{W C}(x, y)$ defined as:

$\operatorname{dist}_{1}(x, y)=d_{W C}(x, y)=\sum_{j=1}^{j=n} w_{j} \times \frac{\left|x_{j}-y_{j}\right|}{x_{j}+y_{j}}$

2) The weighted Gower distance $d_{W G}(x, y)$ defined as:

$\operatorname{dist}_{2}(x, y)=d_{W G}(x, y)=\sum_{j=1}^{j=n} w_{j} \times \frac{\left|x_{j}-y_{j}\right|}{R_{j}}$

3) The weighted Wave-Hedges distance $d_{W W H}(x, y)$ defined as:

$\operatorname{dist}_{3}(x, y)=d_{W W H}(x, y)=\sum_{j=1}^{j=n} w_{j} \times \frac{\left|x_{j}-y_{j}\right|}{\max \left(x_{j}, y_{j}\right)}$

II) The four averages of WESNORD metrics:

$\operatorname{dist}_{4}(x, y)=\frac{d_{W C}(x, y)+d_{W G}(x, y)}{2}$ 


$$
\begin{aligned}
\operatorname{dist}_{5}(x, y) & =\frac{d_{W C}(x, y)+d_{W W H}(x, y)}{2} \\
\operatorname{dist}_{6}(x, y) & =\frac{d_{W G}(x, y)+d_{W W H}(x, y)}{2} \\
\operatorname{dist}_{7}(x, y) & =\frac{d_{W C}(x, y)+d_{W G}(x, y)+d_{W W H}(x, y)}{3}
\end{aligned}
$$

It is clear that the corresponding NSMs are given by:

$$
\operatorname{Sim}_{k}(x, y)=1-\operatorname{dist}_{k}(x, y)
$$

where $1 \leq k \leq 7$.

Finally, the determination of the degree of suitability $S_{k}\left(A_{i}\right)$ of the alternative $A_{i}$ is calculated according to the formula:

$$
S_{k}\left(A_{i}\right)=\sqrt{\operatorname{sim}_{k}\left(A_{i}, D P\right) \times \operatorname{dist}_{k}\left(A_{i}, U P\right)},
$$

where $1 \leq i \leq m$ and $1 \leq k \leq 7$.

As defined, the degree of suitability of the alternative $A_{i}, 1 \leq i \leq m$, is expressed as the geometric mean of its similarity score $\operatorname{sim}_{k}\left(A_{i}, D P\right)$ and its dissimilarity score $\operatorname{dist}_{k}\left(A_{i}, U P\right)$, where $D P$ denotes the desired point formed from the most preferable values of the attributes, and $U P$ the undesired point formed from the least preferred values. The alternatives are then ranked according to the degree of suitability (the highest degree represents the most suitable alternative).

The figure below shows the flowchart of the WESNORD metrics based methodology.

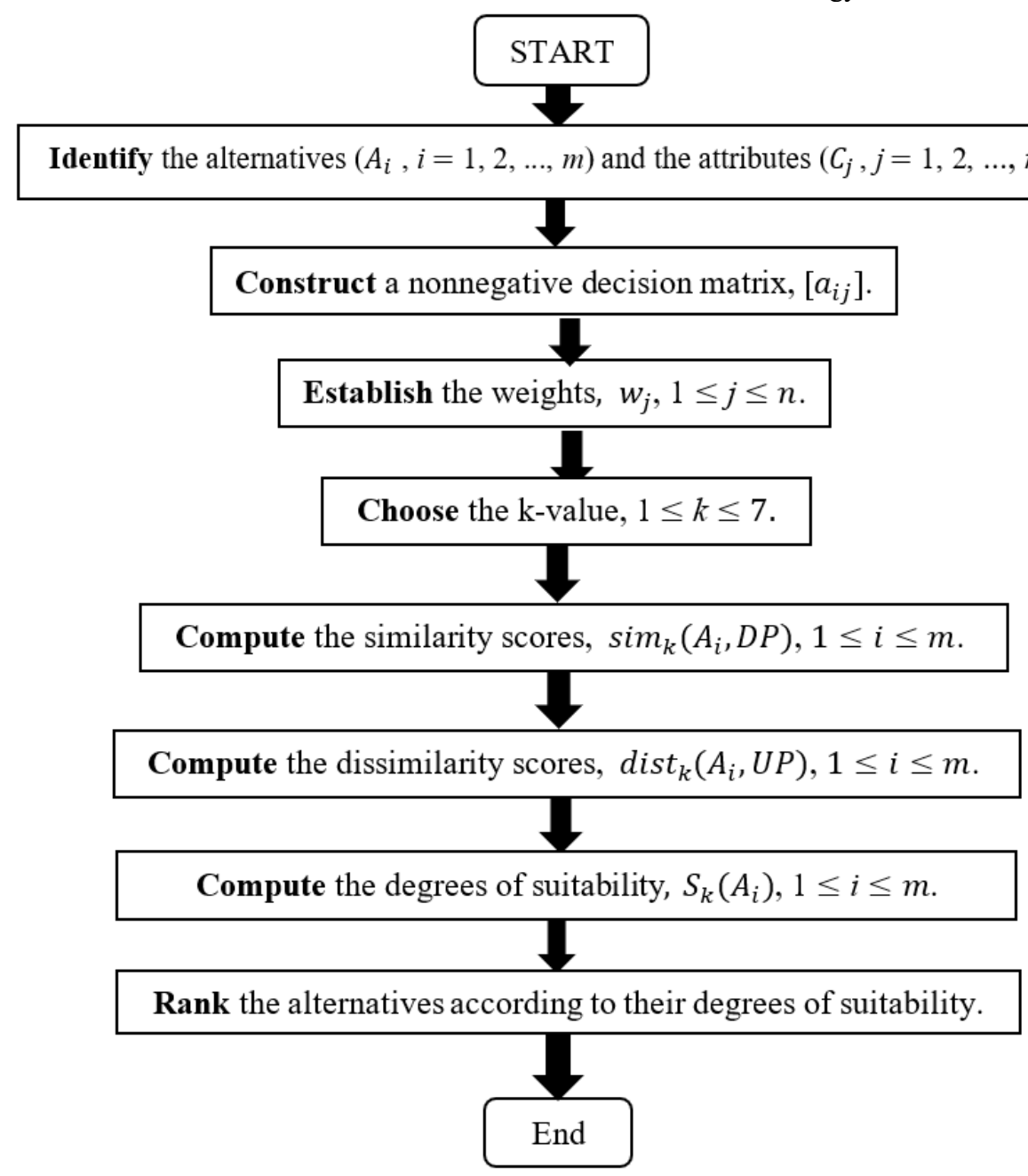

Fig. 1. Flowchart of the WESNORD metrics based methodology 
For demonstration purposes, we provide the following logistics service provider (LSP) selection problem adapted from the paper by Hidouri and Rebaï (2019).

\section{Illustrative example}

\subsection{Problem description}

The problem at hand is to rank thirteen competing logistics service providers (LSPs) $\left(P_{i}, i=1\right.$ to 13). Each LSP is evaluated in terms of his ratings according to five attributes. The five attributes are Responsiveness $\left(C_{1}\right)$, Price $\left(C_{2}\right)$, Delivery time $\left(C_{3}\right)$, Services $\left(C_{4}\right)$, and Quality $\left(C_{5}\right)$. The respective attribute weights are $w_{1}=0.50, w_{2}=0.20, w_{3}=0.15, w_{4}=0.10$, and $w_{5}=0.05$. The LSPs ratings are expressed in the same unitless scale from 0 (worst) to 10 (best). Table 1 below shows the ratings assigned to the thirteen LSPs.

Table 1

Ratings of the LSPs with respect to the attributes

\begin{tabular}{cccccccccccccc}
\hline Attribute & $P_{1}$ & $P_{2}$ & $P_{3}$ & $P_{4}$ & $P_{5}$ & $P_{6}$ & $P_{7}$ & $P_{8}$ & $P_{9}$ & $P_{10}$ & $P_{11}$ & $P_{12}$ & $P_{13}$ \\
\hline$C_{1}$ & 9 & 0 & 1 & 7 & 0 & 1 & 5 & 8 & 8 & 5 & 7 & 5 & 0 \\
$C_{2}$ & 8 & 6 & 7 & 10 & 6 & 6 & 7 & 8.5 & 8.5 & 7 & 6 & 6 & 5 \\
$C_{3}$ & 9 & 0 & 2 & 5 & 0 & 1 & 5 & 5 & 8 & 1 & 0 & 0 & 0 \\
$\mathrm{C}_{4}$ & 5 & 0 & 0 & 8 & 0 & 8 & 3 & 7 & 6 & 1 & 0 & 0 & 0 \\
$\mathrm{C}_{5}$ & 5 & 0 & 0 & 9 & 1 & 1 & 9 & 8 & 8 & 1 & 7 & 7 & 5 \\
\hline
\end{tabular}

As said earlier, after using the WESNORD metrics based RPs to rank the thirteen competing LSPs (from most to least suitable), we will compare the resulting rankings to the reference ranking produced by applying the SAW method with "raw" (not normalized) ratings of the LSPs, using the following three rankings similarity coefficients (see Shekhovtsov and Kołodziejczyk, 2020):

- Spearman coefficient $\left(r_{S}\right)$;

- Weighted Spearman coefficient $\left(r_{W}\right)$;

- Rank similarity coefficient (WS).

\subsection{Ranking results analysis}

The ranking results obtained are summarized in Table 2.

Table 2

Rankings produced by the different RPs and SAW

\begin{tabular}{|c|c|c|c|c|c|c|c|c|}
\hline LSP & dist $_{1}$ & dist $_{2}$ & dist $_{3}$ & dist $_{4}$ & dist $_{5}$ & $\operatorname{dist}_{6}$ & $d_{i s t}{ }_{7}$ & SAW \\
\hline$P_{1}$ & 1 & 1 & 1 & 1 & 1 & 1 & 1 & 1 \\
\hline$P_{2}$ & 13 & 12 & 13 & 13 & 13 & 13 & 13 & 13 \\
\hline$P_{3}$ & 10 & 10 & 10 & 10 & 10 & 10 & 10 & 10 \\
\hline$P_{4}$ & 3 & 3 & 3 & 3 & 3 & 3 & 3 & 4 \\
\hline$P_{5}$ & 11 & 11 & 11 & 11 & 11 & 11 & 11 & 11 \\
\hline$P_{6}$ & 8 & 9 & 9 & 9 & 9 & 9 & 9 & 9 \\
\hline$P_{7}$ & 5 & 5 & 5 & 5 & 5 & 5 & 5 & 5 \\
\hline$P_{8}$ & 4 & 4 & 4 & 4 & 4 & 4 & 4 & 3 \\
\hline$P_{9}$ & 2 & 2 & 2 & 2 & 2 & 2 & 2 & 2 \\
\hline$P_{10}$ & 6 & 7 & 6 & 6 & 6 & 7 & 6 & 7 \\
\hline$P_{11}$ & 7 & 6 & 7 & 7 & 7 & 6 & 7 & 6 \\
\hline$P_{12}$ & 9 & 8 & 8 & 8 & 8 & 8 & 8 & 8 \\
\hline$P_{13}$ & 12 & 13 & 12 & 12 & 12 & 12 & 12 & 12 \\
\hline
\end{tabular}

Based on Table 2, it can be indicated that all seven of these WESNORD metrics lead to the same most suitable LSP, $P_{1}$ and that at the same time, the LSP $P_{9}$ receives the second place, but additionally, except for the weighted Gower distance, the indication of the least suitable LSP is the same.

As said, to measure the resulting rankings similarity to the SAW-produced ranking, the following rank measures of correlation will be employed:

i) The Spearman coefficient $\left(r_{S}\right)$ defined as: 
$r_{S}=1-\frac{6 \sum d_{i}^{2}}{m\left(m^{2}-1\right)}$

where $d_{i}$ is the difference in rankings for each object $i, i \in\{1,2, \ldots, m\}$.

ii) The weighted Spearman coefficient $\left(r_{W}\right)$ expressed as

$$
r_{W}=1-\frac{6 \sum_{i=1}^{m}\left(R x_{i}-R y_{i}\right)^{2}\left(\left(m-R x_{i}+1\right)+\left(m-R y_{i}+1\right)\right)}{m\left(m^{3}+m^{2}-m-1\right)}
$$

$R x_{i}$ and $R y_{i}$ are defined as the position in the ranking of the ith element in ranking $\mathrm{x}$ and ranking $\mathrm{y}$ respectively.

iii) The rank similarity coefficient (WS) given by

$$
W S=1-\frac{\sum_{i=1}^{m} 2^{-x_{i}}\left|R x_{i}-R y_{i}\right|}{\max \left\{\left|1-R x_{i}\right| ;\left|m-R x_{i}\right|\right\}}
$$

Table 3 below summarizes the correlation coefficients values obtained.

Table 3

Correlation coefficients between the rankings provided by the RPs and the reference ranking

\begin{tabular}{cccc}
\hline WESNORD metric & $r_{S}$ & $r_{W}$ & $W S$ \\
\hline dist $_{1}$ & 0.901 & 0.976 & 0.976 \\
dist $_{2}$ & 0.956 & 0.980 & 0.980 \\
dist $_{3}$ & 0.956 & 0.977 & 0.978 \\
dist $_{4}$ & 0.956 & 0.977 & 0.978 \\
dist $_{5}$ & 0.956 & 0.977 & 0.978 \\
dist $_{6}$ & 0.993 & 0.982 & 0.981 \\
dist $_{7}$ & 0.956 & 0.977 & 0.978 \\
\hline
\end{tabular}

From Table 3, we can obviously see that all seven WESNORD metrics perform very well. Besides, the weighted Canberra distance yields the least similarity values than the other ones, but the average of weighted Gower and Wave-Hedges distances leads to the best results. Further, the weighted Gower distance leads to the second best results. Finally, for all the remaining distance metrics, the results are similar to each other. In sum, the values of the similarity coefficients used ascertain the soundness and effectiveness of all seven WESNORD metrics as a useful tool for ranking alternatives.

\section{Conclusions}

To conclude, preliminary normalization in multi-attribute decision-making (MADM) is a necessary and unavoidable stage of the decision process of many methods. Nevertheless, a number of authors have pointed out significant pitfalls associated with normalization methods. One major pitfall, which has been pointed out is that normalization methods may lead to different final rankings of alternatives when a ranking procedure based on them is used for solving a MADM problem. We have investigated, in this work, whether three given primary WESNORD metrics and their averages can be employed effectively in MADM. To ascertain and illustrate the effectiveness of WESNORD metrics based RPs, we have solved a logistics service provider (LSP) selection problem. The obtained results show that the seven RPs used produce final rankings of alternatives, which are very similar to the reference ranking provided by the popular SAW method. The two avenues envisaged for future research involve:

- Carrying out a thorough performance comparison among WESNORD metrics based ranking procedures;

- Applying the WESNORD metrics based ranking procedures to solve real-world MADM problems in various practical fields.

\section{Conflict of interests}

The authors declare that there are no conflicts of interest regarding the publication of this paper.

\section{Funding}

This research did not receive any specific from of funding. 


\section{References}

Aytekin, A. (2021). Comparative analysis of normalization techniques in the context ofMCDM problems. Decision Making: Applications in Management and Engineering, 4(2), 1-27.

Bhowmik, C., Bhowmik, S., \& Ray, A. (2018). The effect of normalization tools on green energy sources selection using multi-criteria decision-making approach: A case study in India. Journal of Renewable and Sustainable Energy, 10(6). https://doi.org/10.1063/1.5043131

Brauers, W.K.M., Zavadskas, E.K., Peldschus, F., \& Turskis, Z. (2006). Multi-objective decision-making for road design. Transport, 23(3), 183-193.

Çelen, A. (2015). Comparative analysis of normalization procedures in TOPSIS method: With an application to Turkish, deposit banking market. Informatica, 24(2), 185-208.

Cha, S.H. (2007). Comprehensive survey on distance/similarity measures between probability density functions. International Journal of Mathematical Models and Methods in Applied Sciences, 1, 300-307.

Ginevičius, R. (2008). Normalization of quantities of various dimensions. Journal of Business Economics and Management, 9(1), 79-86.

Gomes, L.F.A.M., \& Lima, M.M.P.P. (1992). TODIM: Basics and application to multicriteria ranking of projects with environmental impacts. Foundations of Computing and Decision Sciences, 16 (4), 113-127.

Gower, J.C. (1971). A General coefficient of similarity and some of its properties. Biometrics, 27(4), 857-871.

Hajiagha, S.H.R., Mahdiraji, H.A., \& Hashemi, S.S. (2018). Total area based on orthogonal vectors (TAOV) as a novel method of multi-criteria decision aid. Technological and Economic Development of Economy, 24(4), 1679-1694.

Hidouri, M., \& Rebaï, A. (2019). A multi-attribute ranking approach based on net inferiority and superiority indexes, two weight vectors, and generalized Heronian means. Decision Science Letters, 8, 471-482.

Hodgett, R.E. (2013). Multi-criteria decision-making in whole process design. PhD thesis, Newcastle University.

Hwang, C.L., \& Yoon, K. (1981). Multiple attribute decision-making: Methods and applications. New York: SpringerVerlag.

Jafaryeganeh, H., Ventura, M., \& Soares, C.G. (2020). Effect of normalization techniques in multi-criteria decision-making methods for the design of ship internal layout from a Pareto optimal set. Structural and Multidisciplinary Optimization, 62(3), 1849-1863.

Jahan, A., \& Edwards, K.L. (2015). A state-of-the-art survey on the influence of normalization procedures in ranking: Improving the materials selection process in engineering design. Materials and Design, 65, 335-342.

Kaplinski, O., \& Tamošaitien, J. (2015). Analysis of normalization methods influencing results: A review to Honour Professor Friedel Peldschus on the occasion of his 75th Birthday. Procedia Engineering, 122, 2-10.

Keshavarz-Ghorabaee, M., Amiri, M., Zavadskas, E.K., Turskis, Z., \& Antucheviciene, J. (2018). Simultaneous evaluation of criteria and alternatives (SECA) for multi-criteria decision-making. Informatica, 29(2), 265-280.

Keshavarz-Ghorabaee, M.K., Zavadskas, E.K., Turskis, Z., \& Antucheviciene, J. (2016). A new combinative distance-based assessment (CODAS) method for multi-criteria decision-making. Economic Computation and Economic Cybernetics Studies and Research, 50(3), 25-44.

Kosareva, N., Krylovas, A., \& Zavadskas, E.K. (2018). Statistical analysis of MCDM data normalization methods using Monte Carlo approach. The case of ternary estimates matrix. Economic Computation and Economic Cybernetics Studies and Research, 52(4), 159-175.

Lakshmi, T.M., Martin, A., \& Venkatesan, V.P. (2019). A Study on influence of sensitivity analysis on normalization procedures by applying equal and exchange of weight metrics. International Journal of Computer Sciences and Engineering, 7(5), 40-45.

Lance, G.N., \& Williams, W.T. (1967). Mixed data classificatory programs I - Agglomerative systems. Australian Computer Journal, 1(1), 15-20.

Li, D.F. (2009). Relative ratio method for multiple attribute decision-making problems. International Journal of Information Technology and Decision Making, 8, 289-311.

Liao, H.C., \& Wu, X.L. (2020). DNMA: a double normalization-based multiple aggregation method for multi-expert multicriteria decision-making. Omega, 94, 102058.https://doi.org/10.1016/j.omega.2019.04.001.

Maniya, K., \& Bhatt, M.G. (2010). A selection of material using a novel type decision-making method: Preference selection index method. Materials and Design, 31(4), 1785-1789.

McCrimmon, K.R. (1968). Decision Making among Multiple-Attribute Alternatives: A Survey and Consolidated Approach. RAND Memorandum, RM-4823-ARPA; The RAND Corporation: Santa Monica, CA, USA.

Milani, A.S., Shanian, A., Madoliat, R., \& Nemes, J.A. (2005). The effect of normalization norms in multiple attribute decision-making models: a case study in gear material selection. Structural and Multidisciplinary Optimization, 29, 312318.

Mokotoff, E., Garcia, E., \& Pérez, J. (2010). Normalization procedures on multicriteria decision making - an example on environmental problems. Conference: ICEIS 2010 - Proceedings of the 12th International Conference on Enterprise Information Systems, Volume 2, AIDSS, Funchal, Madeira, Portugal, June 8 -12.

Mufazzal, S., \& Muzakkir, S.M. (2018). A new multi-criterion decision making (MCDM) method based on proximity index value for minimizing rank reversals. Computers \& Industrial Engineering, 119, 427-438. 
Muscat, J. (2014). Functional analysis: An introduction to metric spaces, Hilbert spaces, and Banach algebras. Berlin: Springer.

Opricovic, S. (1998). Multicriteria optimization of civil engineering systems. Faculty of Civil Engineering, Belgrade.

Palczewski, K., \& Sałabun, W. (2019). Influence of various normalization methods in PROMETHEE II: an empirical study on the selection of the airport location. Procedia Computer Science, 159, 2051-2060.

Pamucar, D., \& Cirovic, G. (2015). The selection of transport and handling resources in logistics centers using multiattributive border approximation area comparison (MABAC). Expert Systems with Applications, 42(6), 3016-3028.

Pavlicic, D.M. (2001). Normalization affects the results of MADM methods. Yugoslav Journal of Operations Research, 11(2), 251-265.

Ploskas, N., \& Papathanasiou, J. (2019). A decision support system for multiple criteria alternative ranking using TOPSIS and VIKOR in fuzzy and nonfuzzy environments. Fuzzy Sets and Systems, 377(15), 1-30.

Podviezko, A. (2014). Distortions introduced by normalization of values of criteria in multiple criteria methods of evaluation. Proceedings of the Lithuanian Mathematical Society, 55, 51-56.

Podviezko, A., \& Podvezko, V. (2015). Influence of data transformation on multicriteria evaluation result. Procedia Engineering, 122, 151-157.

Rao, R., \& Singh, D. (2012). Weighted Euclidean distance based approach as a multiple attribute decision-making method for plant or facility layout design selection. International Journal of Industrial Engineering Computations, 3, 365-382.

Rozinek, O., \& Mareš, J. (2021). The duality of similarity and metric spaces. Applied Sciences, 11(4), 1910. https://doi.org/10.3390/app11041910

Shekhovtsov, A., \& Kołodziejczyk, J. (2020). Do distance-based multi-criteria decision analysis methods create similar rankings? Procedia Computer Science, 176, 3718-3729.

Stević, Ž., Pamučar, D., Puška, A., \& Chatterjee, P. (2020). Sustainable supplier selection in healthcare industries using a new MCDM method: Measurement of alternatives and ranking according to COmpromise solution (MARCOS). Computers \& Industrial Engineering, 140, 106231.

Vafaei, N., Ribeiro, R.A., \& Camarinha-Matos, L.M. (2018). Data normalization procedures in decision-making: Case study with TOPSIS method. International Journal of Information and Decision Sciences, 10(1), 19-38.

Wen, Z., Liao, H., \& Zavadskas, E.K. (2020). MACONT: Mixed aggregation by comprehensive normalization technique for multi-criteria analysis. Informatica, 31, 857-880.

Yazdani, M., Zaraté, P., Zavadskas, E.K., \& Turskis, Z. (2019). A combined compromise solution (CoCoSo) method for multi-criteria decision-making problems. Management Decision, 57(9), 2501-2519.

Zavadskas, E.K., Turskis, Z., Antucheviciene, J., \& Zakarevicius, A. (2012). Optimization of weighted aggregated sum product assessment. Elektronika ir Elektrotechnika, 122(6), 3-6.

Zavadskas, E.K., \& Turskis, Z. (2010). A new additive ratio assessment (ARAS) method in multicriteria decision-making. Technological and Economic Development of Economy, 16(2), 159-172.

Zavadskas, E.K., Kaklauskas, A., \& Sarka, V. (1994). The new method of multicriteria complex proportional assessment of projects. Technological and Economic Development of Economy, 1(3), 131-139.

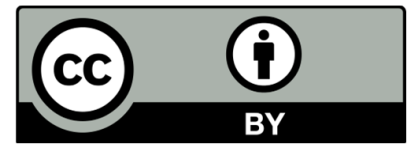

(C) 2021 by the authors; licensee Growing Science, Canada. This is an open access article distributed under the terms and conditions of the Creative Commons Attribution (CC-BY) license (http://creativecommons.org/licenses/by/4.0/). 